Western University Scholarship@Western

FIMS Publications

Information \& Media Studies (FIMS) Faculty

2003

\title{
The Dilemma of Survey Nonresponse
}

Jacquelyn Burkell

The University of Western Ontario, jburkell@uwo.ca

Follow this and additional works at: https://ir.lib.uwo.ca/fimspub

Part of the Library and Information Science Commons

Citation of this paper:

Burkell, J.A. (2003). The dilemma of survey nonresponse. Library and Information Science Research, 25(3), 239-263. 
The Dilemma of Survey Nonresponse

\author{
Jacquelyn Burkell
}

The University of Western Ontario*

* Address for correspondence: Jacquelyn Burkell, Faculty of Information and Media Studies, Middlesex College, The University of Western Ontario, London, Ontario, N6A 5B7. Email: jburkell@uwo.ca. 


\begin{abstract}
An examination of the library and information science (LIS) literature reveals that surveys published between 1996 and 2001 in three major LIS journals have an average response rate of $63 \%$, and almost three quarters of the surveys have a response rate below $75 \%$ (the level that is widely held to be required for generalizability). Consistent with the practice in other disciplines, however, most LIS researchers do not address the issue of nonresponse beyond reporting the survey response rate. This article describes a strategy that LIS researchers can use to deal with the problem of nonresponse. As a first step, they should use methodological strategies to minimize nonresponse. To address nonresponse that remains despite the use of these strategies, researchers should use one of the following strategies: careful justification of a decision simply to interpret survey results despite nonresponse, limiting survey conclusions in recognition of potential bias due to nonresponse, or assessing and correcting for bias due to nonresponse.
\end{abstract}




\section{Introduction}

Surveys are an excellent method for collecting information about the opinions and experience of research participants, and library and information science (LIS) researchers study the needs, challenges and problems of information professionals and information users. It is no surprise, therefore, that surveys are among the most widely used methods in LIS research (Blake, 1994; Callison, 1997; Dimitroff, 1995; Feehan, Gragg, \& Havener, 1987; Fidel, 1993; Goodall, 1996; Julien, 1996; Julien \& Duggan, 2000; McKechnie, Baker, Joyce, \& Julien, 2002; Preitz, 1980-81; Simpson, 1992). Given the prevalence of surveys as a method of collecting data in LIS, issues of survey methodology are of paramount importance to LIS researchers. Specific issues that have been addressed in the LIS literature include optimization of sample design (Lakner, 1998) and the utility of e-mail reminders for surveys sent by regular mail (Roselle \& Neufeld, 1998). Hernon and Schwartz (2000) raise another critical issue in survey methodology: the problem of nonresponse. They remark that, in the LIS literature, "insufficient attention has focused on return rates and whether the population is truly represented" ( $p$ 119), and ask the questions: “... what can be done to get a sufficient number of respondents? ... [H]ow can we frame the imposition to gain cooperation?" (p 118). This article addresses both questions as well as other aspects of the problem of nonresponse.

Well-designed surveys are effective research instruments for gathering quantitative data. When those data are collected from a carefully selected representative sample drawn from a larger population, the results can be generalized beyond the survey respondents to 
the entire population of interest. There is, however, a recurrent problem encountered by virtually all survey researchers that affects this generalization: people who are asked may not respond.

Students of psychology are introduced to the concept of the "blind spot", an area of the retina that receives no direct visual input. Our visual system responds by "filling in" the missing data, relying on information from surrounding areas to provide a best guess about what appears where we cannot actually see. This inductive process works well in a smooth and continuous world where the seen is a good approximation of the unseen. The process fails, however, when new and unexpected visual information is contained completely within the boundaries of the blind spot. In this case, startling and potentially important information goes completely unnoticed.

Survey researchers have an analogous blind spot to contend with: the missing data that result from nonresponse. The researcher receives little or no information from nonrespondents, and is faced with the challenge of forming a complete picture of the surveyed population from incomplete data. The solution most often adopted is simply to fill in the gap with information collected from respondents, assuming that their data provide a good approximation for that missing from nonrespondents. This solution works well if nonrespondents do not differ from those who provide data, but it fails if the two groups are different in ways that influence their survey responses. When survey results are generalized to the population in this latter case, it is as if the nonrespondents do not 
exist: the population that is described by the survey results is the population of respondents only.

The consequences of nonresponse for conclusions based on survey data can be serious. Library patron satisfaction would be overestimated if those less happy with library services were also less likely to respond to a satisfaction questionnaire. Librarian workload would be underestimated if those busiest in their work could not find the time to complete the survey. Academic libraries faced with the difficult decision of whether to discontinue journal subscriptions might use a survey to collect patron input on the question, only to be misled about the needs of the general population if those who do not use the journals simply do not respond to the survey. In each of these cases, the data from nonrespondents would have changed the survey conclusions.

Nonresponse introduces an unresolvable dilemma: ultimately, assessment of, and correction for, nonresponse requires that researchers either estimate data for or extract data from those who have not provided any. This dilemma is a central issue in survey methodology. In fact, an entire conference was recently devoted to nonresponse (International Conference on Survey Nonresponse, 1999, Portland Oregon, proceedings published as Groves, Dillman, Etlinge, \& Little, 2001). It is widely held that a response rate of $75 \%-90 \%$ is sufficient to support generalizations from the surveyed sample to the population of interest (Ary, Jacobs, \& Razavieh, 1996; Gall, Borg, \& Gall, 1996; Kerlinger, 1986; Tuckman, 1999). Overall, however, only about 70\% of those approached agree to complete a survey, and there is evidence that nonresponse is 
increasing over time (Brehm, 1993). Surveys of some groups show even lower response rates: for example, approximately $60 \%$ of physicians respond to survey requests (Cummings, Savitz, \& Konrad, 2001; Sibbald, Addington-Hall, Brenneman, \& Freeling, 1994). LIS researchers also face the problem of nonresponse. An examination of LIS survey research, reported in more detail below, reveals an average response rate of $63 \%$. Thus, most surveys published in LIS and in other disciplines show some degree of nonresponse, and many have response rates that do not meet the level required for generalizing beyond those actually surveyed to the population of interest.

There is no doubt that survey nonresponse is a ubiquitous problem. The real question is: How are researchers to deal with the issue? Most research methods textbooks provide little if any guidance. Among the subset that note the problem of nonresponse, some discuss methodological variations that improve response rates (e.g., Neuman, 2000), and a still smaller group provide general guidelines about how to assess the impact of nonresponse (e.g., Palys, 1997). Detailed discussions of statistical approaches to assess and possibly correct for nonresponse are usually limited to specialized works in survey methodology (e.g., Groves Dillman, Etlinge, \& Little, 2001). The situation is no better within the discipline of LIS: of three methods textbooks widely used in LIS (Busha \& Harter, 1980; Losee \& Worley, 1993; Powell, 1997), only one (Losee and Worley) mentions the issue of nonresponse, and the treatment in that text is cursory. LIS survey researchers, therefore, are largely left on their own with regard to nonresponse. They know there is a problem, but they are not exactly sure what to do about it. 
This article addresses the dilemma of nonresponse by providing a general overview of the problem along with a detailed discussion of the various approaches that LIS researchers can use to minimize both the degree of nonresponse and the impact of nonresponse on survey results. The final section of the article provides an overview of the treatment of nonresponse in the LIS literature. This overview is based on an examination of surveys published in three prominent LIS journals over the years 1996-2001 identifying the degree of nonresponse in these surveys and the degree to which researchers use strategies to address the nonresponse problem.

1.1 What is nonresponse and why is it important?

Survey nonresponse refers to the discrepancy between the group approached to complete a survey and those who eventually provide data. Despite the best intentions and best efforts of researchers, it is rare that data are actually collected from each member of the identified sample, and most surveys that achieve a perfect response rate (especially those with larger and more diverse samples) do so at significant cost in terms of researcher effort and financial resources. In the majority of surveys, a relatively large proportion of those chosen for the sample do not participate, as a result of either unsuccessful attempts to contact or failure to complete the survey.

Although the causes and consequences of nonresponse differ from survey to survey, some general conclusions are supported by previous research. These studies provide some insight into the profile of survey respondents (as compared to nonrespondents), allowing researchers to make educated guesses regarding differences between 
respondents and nonrespondents, and suggesting changes to survey administration that might help to improve response rates.

Those who respond to a survey tend to be more interested in the topic of the survey and/or more interested in the activities being studied (Donald, 1960; Martin, 1994; Senf, 1987), and respondents are more likely to believe that survey responses (including their own) will be used to make changes (Rogelburg, Luong, Sederbury, \& Cristol, 2000). Individuals give the following reasons for not returning mail surveys: they did not receive it; they were too busy; they forgot it or lost it; they were not interested in the topic; the survey was too long; or they thought it was not intended for them (Robinson \& Agisim, 1951; Sosdian \& Sharp, 1980). It is interesting to note that the profile of respondents in surveys of the general public matches that of public library users (Berelson, 1949): respondents tend to be female, older, and more educated than nonrespondents (Green, 1996; Kaldenberg, Becker, \& Boris, 1994).

Organizational representatives cite reasons for refusal to complete a survey that are similar to those cited for individual nonresponse, including inconvenience, inappropriate or irrelevant subject matter, concern about the confidentiality of the information provided, time constraints, survey length, and lack of benefit to the organization (Albaum, Evangelista \& Medina 1998; Baldauf, Reisinger, \& Moncrief, 1999; Diamantopoulos \& Schlegelmilch, 1996; Tomaskovic-Devey, Leiter, \& Thompson, 1994). When organizations are the population of interest, organizational size is an 
important determinant of response: larger organizations are less likely to respond to surveys (Cotton \& Wonder, 1982; Tomaskovic-Devey et al., 1994).

Nonresponse presents two problems for the interpretation of research results. First, it reduces the sample size and, thus, decreases the precision with which results can be stated. Second, and more importantly, it introduces error into the sampling process by excluding a non-random subset of the population. If the excluded subset is different from those remaining with regard to the survey data, the results of the survey will be biased. The first issue, if it occurred alone, would be neither particularly serious nor particularly difficult to remedy. In most cases (except where a census has been attempted), additional respondents can be recruited in numbers sufficient to compensate for expected refusals. If this strategy is not feasible, statistical techniques automatically account for smaller sample size by increasing the confidence intervals around estimates of population parameters or by decreasing the significance of inferential statistics. Unfortunately, both of these responses to a smaller sample are valid only if the results are unbiased, that is if the data provided by respondents are representative of the entire population. When nonrespondents differ significantly from those who do respond in their survey responses, increasing the size of the sample or using statistics that reflect sample size without addressing the bias due to nonresponse can serve only to bolster reader confidence in potentially inaccurate results.

Nonresponse always introduces some bias into the sample, even if that bias cannot be detected by statistical tests on available comparison measures. Nonresponse results 
directly from subject choice (e.g., the choice not to complete the survey) or subject characteristics (e.g., the characteristic of having moved and therefore having an invalid mailing address). In these choices and/or characteristics, nonrespondents by definition differ from respondents. The groups will also differ in the qualities that determine the choices and/or are correlated with the characteristics. Thus, public library patrons who choose not to complete a survey regarding the importance of Internet access are also likely to be those who use the service less, and the group of librarians who do not receive a job satisfaction survey because they have changed positions is likely to include many who changed jobs because they were dissatisfied with their work. Occasionally, researchers argue that if they cannot identify any systematic difference between respondents and nonrespondents, there is no bias due to nonresponse. Statistical comparisons of respondents and nonrespondents on available descriptors, however, can only eliminate the possibility that the two groups differ significantly in terms of the measured qualities. It remains possible, and even likely, that there are differences between the groups: either real differences on the measured variables too small to reach statistical significance, or differences on other variables for which the data are unavailable.

The question, therefore, is not whether nonresponse has resulted in a biased sample: the answer to that query is always 'yes'. The important issue is whether the bias influences survey results. There is, however, a dearth of direct research on this question, for a very good reason: the degree to which nonresponse affects survey conclusions depends on the relationship between the variable(s) of interest and the cause(s) of nonresponse (Brehm, 
1993), and this relationship is likely to differ from survey to survey. If there is no relationship, nonresponse will not affect the survey results. If, however, there is a relationship (either direct or through a third variable that influences both nonresponse and the dependent variable(s) of interest), nonresponse will compromise the survey conclusions. If researchers were able to measure the relationship between selection mechanisms and survey results for their particular survey, it would be simple to determine whether nonresponse represented a threat. The nature of that relationship, however, is virtually impossible to determine, since assessing it requires the very thing that nonresponse precludes: analysis of data from nonrespondents.

This is in fact the central dilemma of nonresponse: the impact of nonresponse on survey data cannot be determined without data (either actual or estimated) from nonrespondents. Nonresponse raises the spectre (but not the certainty) of biased results; furthermore, the higher the level of nonresponse, the greater the potential bias (Alexander, Alliger, \& Hanges, 1984; Chen, 1996; Cochran, 1963; van Goor \& Stuyiver, 1998; Viswesvaran, Barrick, \& Ones, 1993). In isolated cases, researchers have demonstrated that low response rates do not necessarily compromise survey results (Keeter, Miller, Kohut, Grovers, \& Presser, 2000; Visser, Krosnick, Marquette, \& Curtin, 1996). This should not be taken, however, as general evidence that nonresponse can be ignored. The important issue is representativeness - whether the respondents resemble (with regard to survey results) the population from which they were drawn (Cook, Heath, \& Thompson, 2000; Cook \& Thompson, 2001; Krosnick, 1999; Thompson, 2000). It is possible to interpret survey results even with high levels of nonresponse if it can be argued that the 
respondents are representative of the population. Thus, for example, Cook and Thompson (2001) argue that, despite a response rate of approximately 14\% (Thompson, 2000), the results of a web-based LibQUAL+ study can be generalized to the larger population because the respondents are shown not to differ significantly from the population on a variety of measured variables (Thompson, 2000). The approach used by Cook and Thompson is one strategy for dealing with nonresponse. The next section of this article presents this and other suggestions for addressing with the dilemma of nonresponse.

2 Dealing with the Dilemma

As a first strategy for dealing with nonresponse, the researcher should address the problem at the source by taking advantage of methodological variations proven to reduce nonresponse. Although these efforts are important, in most cases they will not results in $100 \%$ response. The researcher is left, therefore, with the problem of interpreting survey results in the context of some remaining level of nonresponse.

Reports of survey results should always indicate the degree to which initially selected respondents participate in the survey by reporting the response rate (response rate $=1$ nonresponse rate). There are a number of definitions of response rate, differing in the way that incomplete surveys, non-contacts, refusals, and other outcomes are treated (American Association for Public Opinion Research (AAPOR), 2000). This article uses the 'maximum response rate' as defined by AAPOR: response rate $=($ complete responses + partial responses)/total number in the eligible sample. When the response 
rate is less than $100 \%$, the researcher has three choices: (1) ignore the nonresponse, preferably on a substantive basis (e.g., a low level of nonresponse, or documented reason to believe that nonresponse would not affect research results); (2) limit the survey conclusions based on the rate and presumed impact of nonresponse; or (3) attempt to assess and (if necessary) correct for the sampling bias introduced by nonresponse.

\subsection{Addressing the Problem at the Source: Methods to Reduce Nonresponse}

The method of survey administration is an important determinant of response rates. Four methods that are widely used in surveys are mail, telephone, face-to-face, and e-mail administration (note that some surveys are also distributed by fax, but these are few in number, and the method has quickly been supplanted by e-mail administration). Surveys have also been delivered over the Web (e.g., Perkins \& Yuan, 2001), but Web surveys of probability samples generally require recruitment of respondents using one of the other means of administration (Couper, 2000). Of the four methods widely used when a representative sample is desired, face-to-face administration tends to result in the highest response rates (Hox \& Deleeuw, 1994), although this effect may differ across demographic groups (Krysan, Schuman, Scott, \& Beatty, 1994). Telephone surveys demonstrate the next highest response rates, followed by regular mail and then electronic mail (Hox \& Deleeuw, 1994; Kettleson, 1995).

Although response rates are lowest for mail and e-mail delivery, these are also the least expensive methods of administration, and therefore they are widely used in survey 
research. Dillman (2000) has developed a "tailored design method" to reduce the error associated with nonresponse (among other factors) in mail and e-mail surveys. He suggests that survey response can be maximized by: (1) establishing the respondent's trust; (2) increasing the expected rewards of participation; and (3) reducing the social costs of participation. Some of the specific strategies suggested by Dillman are relatively low-cost and simple to implement in any survey. These include prenotification, personalized cover letters, the use of reminders, incentives with the invitation to participate, and stamped, self-addressed envelopes for the return of mail surveys. Research suggests that, of these methods, small (i.e., \$1-\$2) monetary incentives included with the initial survey mailout are the single most effective strategy that researchers can use to increase response rates (Church, 1993; Fox, Crask, \& Kim, 1988; Gajraj, Faria, \& Dickinson, 1990; Helgesen, Voss, \& Terpeting, 2002; Hopkins \& Gullikson, 1992; Singer, Hoewyk, \& Maher, 2000). Meta-analyses of studies of mail survey response rates have offered support for the strategies suggested by Dillman (Fox et al., 1988; Hopkins \& Gullickson, 1992; Yammarino, Skinner, \& Childers, 1991), indicating that the impact of interventions to increase response rates is consistent across populations (Green, Boser, \& Hutchinson, 1998). Hart (1998) used many of Dillman's suggestions for a survey of the relationships between work roles and information gathering for college faculty, and achieved a response rate of $84 \%$.

In addition to these strategies, researchers should consider selecting a smaller initial sample and concentrating efforts and resources on achieving a high response rate (Wayne, 1975-76). Researchers may choose to use one of the more expensive methods to 
collect data from the smaller sample (e.g., telephone interviews), they may choose to use multiple methods in soliciting response (Roselle \& Neufeld, 1998), or may provide incentives to those invited to participate. Although a smaller sample limits the precision with which results can be stated, this disadvantage is offset by the reduction in bias associated with an increased response rate.

\subsection{Ignoring Nonresponse}

When can you simply ignore nonresponse? The short answer, correct in the most absolute sense, is never. Although low response rates do not necessarily compromise survey results (Keeter, Miller, Kohut, Groves, \& Presser, 2000; Krosnick, 1999, Visser, Krosnick, Marquette, \& Curtin, 1996), any level of nonresponse could bias conclusions (Jones, 1996). The real problem is that the researcher cannot know whether nonresponse affects survey conclusions, since this requires information about the differences between respondents and nonrespondents. Nonetheless, some conditions can justify for ignoring the nonresponse, and the factors that should be taken into account are outlined in this section. Researchers should not, however, see this as a panacea or default strategy for dealing with nonresponse. Ignoring the problem is appropriate only in a small proportion of cases, and the researcher must ensure that the use of the strategy is explicitly justified.

First, the impact of nonresponse on survey results depends entirely on the relationship between the mechanisms that result in nonresponse and the variables of interest. Again, by definition, the researcher is not in a position to measure this relationship because the required data are unavailable. It is possible, however, to hypothesize about the 
relationship. To the extent that the researcher can make a strong logical case that the likelihood of response is unrelated to survey conclusions, there is some justification for ignoring nonresponse.

Second, the degree of nonresponse is obviously important. Potential bias increases monotonically with nonresponse (Alexander, Alliger, \& Hanges, 1984; Chen, 1996; Cochran, 1963; van Goor \& Stuiver, 1998; Viswesvaran, Barrick, \& Ones 1993): the higher the level of nonresponse, the greater the potential bias. Given that any degree of nonresponse can lead to bias in survey results, it is difficult if not impossible to identify an acceptable level of response. Nonetheless, it is widely held that a response rate of $75 \%$ - $90 \%$ is sufficient to support generalization. If the response rate for a survey is above $90 \%$, researchers are probably justified in generalizing from the sample to the population. If the response rate falls between $75 \%$ and $90 \%$, generalization may be justified, particularly if other conditions identified in this section are also met. When survey response rates fall below $75 \%$, straightforward generalizations from sample to population are tenuous at best, and the data should probably be subjected to some of the other procedures outlined in this section to assess and possibly correct for bias due to nonresponse.

Third, the type of research is important. Nonresponse is less serious for preliminary research or research designed to support theory development. This arises, in part, because such studies are rarely interpreted alone. In addition, many studies of this type focus on 
relationships between multiple variables that (as discussed below) may be less influenced by nonresponse.

Finally, there is some evidence that the impact of nonresponse is greater for the estimation of univariate population parameters (e.g., average age of library users) than for the estimation of bivariate correlations (e.g., relationship between age and library resource use), multivariate relationships (e.g., faculty status, salary, and library size as predictors of librarian job satisfaction), or tests of differences between groups within the larger sample (e.g., comparison of the effectiveness of bibliographic instruction for faceto-face versus distance learners). Care must be taken, however, in the application of this criterion. Although a smaller impact of nonresponse on bivariate and univariate relationships has been observed in empirical data (Goodman \& Blum, 1996; van Goor \& Verhage, 1999) and there is some theoretical basis to assume that the observation is

correct (Alexander, Barrett, Alliger, \& Carson, 1986), this conclusion is not unchallenged. Brehm (1993) presents convincing theoretical evidence and supporting Monte Carlo simulation data demonstrating that, nonresponse can have a large biasing effect on multivariate relationships if the selection criteria and the dependent variable of interest are related.

\subsection{Limiting Survey Conclusions}

The discussion above indicates that, in many cases if not most, it is inappropriate simply to ignore nonresponse. An alternative strategy is to limit survey conclusions commensurate with the level of nonresponse. If the survey response rate is below $75 \%$, 
the researcher should, at minimum, ensure that the reader is aware of the limitation to the generalizability of survey results arising from nonresponse. A better approach may be to assume that nonresponse has introduced bias in survey results; it is then possible to estimate the likely impact of that bias using statistical techniques. These techniques work by making assumptions (worst case or average case) about how nonrespondents might have answered, and using this information to reduce the precision with which results are stated. There are procedures available for calculating the maximum amount of bias introduced by nonresponse in a univariate population estimate such as the estimate of average job satisfaction among librarians (Alexander, Alliger, \& Hanges, 1984; Chen, 1996; Cochran, 1963). Some survey analyses include subgroup comparisons, such as an examination of the compliance of small, medium, and large public libraries with recommendations regarding Internet connectivity. When subgroup differences are tested using t-tests or analyses of variance, it is possible to estimate the degree to which such differences are affected by nonresponse (Viswesvaran, Barrick, \& Ones, 1993). These techniques effectively reduce the precision of survey results to compensate for sampling bias resulting from nonresponse. Unless response rates are very high, however, they tend to be overly conservative, and researchers who use these approaches are likely to underestimate the significance of their results. Thus, these statistics are not widely used because they work best when they are needed least: at low levels of nonresponse.

2.4 Assessing and correcting for sampling bias due to nonresponse A more widely used approach to the issue of nonresponse is to attempt to determine whether nonresponse has introduced sampling bias and to correct that bias if it is found. 
The most commonly used strategy compares respondents to a second group that either includes or represents nonrespondents using one of the three specific strategies presented below. Qualitative comparisons (e.g., Clougherty, Forys, Lyles, Persson, Walters, \& Washington-Hoagland, 1998; Hart, 1998) provide some insight into the impact of nonresponse, but a better approach is to test the statistical significance of any observed differences. A significant difference between respondents and the comparison group suggests the presence of sampling bias. If such a difference is found, researchers can attempt to correct the bias by re-weighting the data to account for the underrepresentation of subgroups resulting from the nonresponse (see section 2.5).

The respondents can be compared to the population from which they were drawn, in an attempt to answer the question: Do respondents represent a random sample of the population? The application of this approach is limited to comparisons for which data are available both for respondents and for the population as a whole - generally demographic descriptors. A statistical test is applied to these data to determine the probability that the sample of respondents is drawn from the population. The appropriate statistical test depends on the level of measurement of variable being compared (interval or ratio versus ordinal or nominal) and, for interval or ratio variables, what is known about the population distribution (see Table 1).

Insert Table 1 about here

A second approach is based on research indicating that nonrespondents are more like late responders than early responders in both expressed attitudes and demographics (Dalecki, 
Whitehead, \& Blomquist, 1993; Green, 1991; Pearl \& Fairley, 1985). In this approach, the group of respondents is divided into at least two subgroups: early respondents and late (or reluctant) respondents. The division can be based on factors such as the time elapsed between initial mailout and response, or the number of reminders required before response. The choice of statistic to compare the groups depends on the number of groups identified and the level of measurement of the variable of interest (see Table 2).

A third approach is to compare respondents to nonrespondents on variables that are available for both groups. If respondents from the original sample can be identified (e.g., through numeric keys on mailed out surveys), it is possible also to identify nonrespondents. In this case, external data sources can provide information about both groups (e.g., administrative data might be available for the entire sample). Crawford and Rice (1997) use this strategy to conclude that there is no significant bias due to nonresponse in their survey of the effects of automation on liberal arts college libraries. Alternatively, subjects can explicitly be offered the option to refuse to complete the survey, and subjects who refuse can be asked to answer a small number of questions (Senf, 1987). This strategy, which is a version of the 'door-in-the-face' technique for inducing compliance (Cialdini, Vincent, Lewis, Catalan, Wheeler, \& Darby, 1975), may allow a small amount of data to be collected from people who do not complete the entire survey. Table 2 identifies the appropriate statistic for the comparisons between respondents and nonrespondents. 
The first and third approaches outlined above are limited by the data available for the two groups to be compared (usually this is restricted to demographic information). Thus, with these approaches it is only possible to assess sampling bias with respect to these variables, and not with respect to the substantive survey data. The second approach allows direct comparison of survey responses, but it is based on the (possibly incorrect) assumption that nonrespondents can be adequately represented by reluctant respondents. Obviously, a better way to assess the impact of sampling bias is to compare directly survey data for respondents and nonrespondents (Fuller, 1974). Deming (1960) suggests a method to accomplish exactly this: select a random subset of nonrespondents, and pursue $100 \%$ response from these individuals. The data collected from these converted nonrespondents can be compared to data from the initially responding sample to identify the degree of bias due to nonresponse on any variable measured by the survey.

This last strategy may, in fact, represent the best way to address the impact of nonresponse on survey data. There are only two factors that researchers should consider. First, gathering data from a sample of initial nonrespondents is likely to be time consuming and expensive. Second, care should be taken that the process of gathering the data from these initial nonrespondents has minimal impact on the responses themselves. For example, the researcher should be aware that lack of time may have prevented these individuals from responding. If this is the case, the researcher must take special care to 
find an opportunity for data gathering when the respondent has sufficient time to devote to the process; otherwise, the data collected could be of questionable quality. Ultimately, if this procedure is followed, the researcher may choose to limit the data collected to only the most important survey questions as a way to minimize both the costs of collecting the data and the imposition on the already reluctant respondent.

\subsection{Adjusting for sampling bias due to nonresponse}

When sampling bias is identified using the methods outlined above, reweighting of obtained data is the strategy most frequently used to compensate for sampling bias due to nonresponse. Using a statistical package such as SPSS, selected cases can be given additional weight in analyses. The weighting factors are chosen to remedy the difference between sample proportions and population proportions for various subgroups. For example, if the population is split evenly between men and women (50\% in each group), but $60 \%$ of the respondents are men, weights can be applied to compensate for the difference. The weight applied to each respondent is calculated as the population proportion/sample proportion. In this case, the weight for male respondents would be $50 \% / 60 \%$, or .8333 . The weight applied to female respondents would be $50 \% / 40 \%$, or 1.25. When statistics such as averages are calculated over the weighted data, it is as if the sample was split 50/50 in terms of gender. Holt, Elliott, and Moore (1999) used an alternative, mathematically equivalent, method for calculating weights. They calculated the weight of each case as the number in the weighting class for the entire population/the number in the weighting class for the sample. For a more detailed discussion of 
weighting and other statistical techniques to compensate for nonresponse, see Groves (1989), Groves et al. (2001), Little and Rubin (1987), or Kalton (1983).

Although weighting is widely used to compensate for nonresponse, weighting adjustments are not always effective in reducing bias (Brehm, 1993; van Goor \& Stuiver, 1998), and, in some cases, they may even exacerbate the problem (Brehm, 1993). Essentially, the process of weighting replicates respondents within each weighting class to compensate for those within the class who did not respond. Thus, weighting is based on the assumption that within each weighting class there are no systematic differences between respondents and nonrespondents (Mandell, 1974). If this assumption is not met (and without actually collecting data from nonrespondents there is no way to determine whether it is), weighting cannot compensate for the sampling bias introduced by nonresponse. More complex modeling approaches (Achen, 1986; Glynn, Laird, \& Rubin, 1986; Heckman, 1976, 1979; Heckman \& Robb, 1986) are less susceptible to this criticism, although these approaches require that the researcher make assumptions about the relationship between the likelihood of participation and the variables of interest (Brehm, 1993; Wainer, 1989). Deming (1960) suggested the only approach that does not require assumptions about the nature of either the mechanisms that result in nonresponse or the data that would have been obtained from nonrespondents. In that approach, the data from the converted nonrespondents represents that from the entire group that did not respond. If the researcher is successful in collecting data from a random subset of the original nonrespondents, appropriate weighting of the data provided by this group will adequately correct for nonresponse bias. 


\section{Nonresponse in the LIS Literature}

Summaries of surveys published in a variety of disciplines have indicated that, although response rates are low enough to constitute an issue for the interpretation of results, a large proportion of published articles fail to respond to the issue (Cummings, Savitz, \& Konrad, 2001; Lindner, Murphy, \& Briers, 2001). In this section of the paper, we attempt to determine whether a similar situation exists in the LIS literature. Specifically, an empirical study of surveys published in LIS will be used to examine the following questions:

- What is the extent of nonresponse in surveys published in the LIS literature and how serious is this level of nonresponse for the interpretation of survey results?

- What methodological strategies do researchers take to reduce nonresponse?

- Do researchers attempt to determine the degree of and/or statistically account for nonresponse bias, and if so, how?

Conclusions are based on a census of surveys published in the years 1996-2001 in three

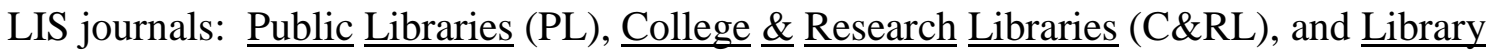
$\underline{\&} \underline{\text { Information }} \underline{\text { Science }} \underline{\text { Research }}$ (LISR). The years 1996-2001 represent the most recent 6 full years of publication for these journals at the time the census was completed. This constitutes a purposive sample, chosen to cover a broad range of recent LIS research in both academic and public library settings. It is recognized that the surveys examined are not a random sample of surveys published in LIS, and therefore care must be taken in generalizing beyond the specific results. The purpose, however, is only to determine 
whether nonresponse and the treatment of it are a problem in the LIS literature, and not to draw quantitative conclusions about the degree of the problem. The purposive sample described is sufficient, if not ideal, to meet those needs.

The surveys selected met the following criteria:

- The goal of the survey was to describe the population of interest (thus, surveys were not included if there was no intention to apply results to the population);

- Either the entire population was selected for participation (a census), or the selected participants represented a random sample of the population;

- The response rate was reported.

Appendix I presents the list of articles presenting the surveys used in the analysis. From the published report of each survey, information was extracted regarding the response rate, the methodological strategies employed to reduce nonresponse, and any attempts to assess and/or correct for bias due to nonresponse (see Table 3 for details). In many of the reports examined, the methodological details are sketchy (this is consistent with the results of McKechnie, Baker, Joyce, \& Julien, 2002). For the purposes of this analysis, it is assumed that methodological variations are not used unless they are explicitly mentioned in the report. It is recognized that any bias that arises from this assumption will lead to the underestimation of the use of the strategies. Details such as these, however, should be included in the methods descriptions of published studies, and therefore the assumption is deemed appropriate.

Insert Table 3 about here 


\subsection{Results}

During the years 1996 to 2001, 76 surveys reported in 72 articles (one article included 3 surveys, and two others included 2 surveys each) met the criteria for inclusion. Library representatives (usually the library director) were the most frequently surveyed group (32 surveys, 42.1\%). Librarians responding as individuals and not representatives of the library were the target population in 21 surveys $(27.6 \%)$, while users (e.g., faculty, students, medical patients) made up the population for 23 surveys (30.3\%).

\subsubsection{Survey nonresponse in the LIS literature}

The average response rate across all surveys examined was 62.9\% (s.d.=19.6), and 21 surveys $(27.6 \%)$ have response rates $75 \%$ or above. The data are broken down by journal (see Table 4), by year (see Table 5), by population type (see Table 6) and by research goal (see Table 7). Inferential tests for the impact of these variables on response rate are inappropriate given that the data represent a population census, but effect sizes, indicating the proportion of response rate variability that is accounted for by each independent variable, can be calculated. Effect sizes are below .1 (less than $10 \%$ of variance accounted for) for journal, year, and research goal, suggesting that these variables have little impact on response rate. Population type, however, accounts for over $25 \%$ of the variance in response rate (effect size of .256), with library representatives showing the highest response rates (72\%), followed by librarians (65\%) and other groups (49\%). 
Nonresponse is an issue in LIS research. Although the average response rate is relatively high, approximately $1 / 3$ of those identified for survey participation do not provide data. Furthermore, almost $3 / 4$ of the surveys examined have response rates below that generally required for generalizability.

Insert Table 4 about here

Insert Table 5 about here

Insert Table 6 about here

Insert Table 7 about here

\subsubsection{Use of methodological variations to reduce nonresponse}

Method descriptions for each survey were examined to determine details about the survey administration. The vast majority of the surveys $(66$, or $86.8 \%)$ were administered by mail, with five surveys (6.6\%) administered by email, three (3.9\%) administered by telephone, and the remaining two surveys (2.6\%) administered using other means (e.g., hand delivery or combination of methods). The majority of surveys were delivered to a specific, named individual (67, or $88.2 \%)$, and in almost half of the surveys (37, or $48.7 \%$ ) at least one reminder was sent to survey respondents. Only ten of the surveys 
(15.2\% of the mailed surveys) provided respondents with a self-addressed, stamped envelope for survey return, and four (3.9\%) sent pre-notification of the survey to potential respondents. Only six surveys (7.9\%) used incentives. Despite the fact that prepaid monetary incentives have been demonstrated to be most effective, all incentives were non-monetary, and at least five were offered for survey completion rather than being included with the survey when it was delivered (it was impossible to tell from the method description of the sixth survey whether the incentive was offered initially or for completion only). Thus, the data show that many methodological variations proven to increase response rates were not widely used in the surveys studied, and those variations that were employed were not always used in the most effective manner possible.

\subsubsection{Assessment of and correction for response bias}

A total of nine surveys (11.8\%) explicitly addressed the issue of nonresponse beyond simply acknowledging response rate. One assessed the bias arising from nonresponse and corrected by reweighting the results. Another presented the results of statistical comparisons of respondents with the population of interest, but no significant differences were identified and therefore no correction was attempted. Finally, seven reports presented either population parameters or comparative data for respondents and nonrespondents but did not test for significant differences between the groups. The large majority of surveys examined, therefore, do not address the issue of nonresponse beyond reporting response rate.

\subsection{Discussion}


The results of this survey, though not generalizable to all surveys published in the LIS literature, suggest that LIS researchers are not immune to the problem of nonresponse. The average response rate for the surveys identified in the three journals studied is $63 \%$, a value that is comparable to the average response rate of $61 \%$ observed for surveys of physicians over the years 1986-1995 (Cummings, Savitz, \& Konrad, 2001). Although the average rate of response is relatively high, it is important to note that almost three quarters of the surveys examined had response rates lower than $75 \%$, a level that is traditionally held to be required for generalization from sample to population. Furthermore, the majority of surveys in LIS are conducted to describe a population, rather than to test or develop a model, which is significant because these types of results will be most affected by nonresponse.

The highest average response rates were observed for surveys of library representatives, followed by those of librarians, and finally surveys of user groups (e.g., faculty). This ordering of response rates may be explained by the higher response rates generally observed for surveys that are of intrinsic interest to those completing them (Donald 1960; Martin, 1994; Senf, 1987); given that the general focus of research published in LIS is libraries and information services, it seems likely that libraries and librarians would be more interested in the topics than would members of user groups.

It appears that LIS researchers could do a better job of minimizing nonresponse and implementing strategies to improve the interpretation of survey results in the context of nonresponse. There is little utilization of methodological variations that have been 
demonstrated to improve response rates. Almost all surveys reported in these three journals over the years 1996-2001 use traditional mail or e-mail as the method of survey delivery. Few studies use prenotification, reminders, self-addressed stamped envelope for survey returns, or incentives to encourage high response rates. Furthermore, those studies that provide incentives implement them in a relatively ineffective manner: they generally offer non-monetary incentives for completed surveys rather than including a small monetary incentive with the initial survey delivery. Only a small proportion of studies acknowledge the possibility of sampling bias due to nonresponse and attempt to assess or correct for that bias.

\section{Conclusion}

Nonresponse presents a virtually unresolvable dilemma: in order to know whether nonresponse has biased survey results, researchers must know (or guess at) the data that nonrespondents would have provided. The strategies provided in this article do not eliminate the dilemma. They merely represent a best possible response to an impossible problem. That being said, it is evident that survey nonresponse is an issue in LIS, as it is in other disciplines, and LIS researchers need strategies for minimizing the problem of nonresponse and the impact of nonresponse on survey conclusions. To achieve these goals, the following strategies are suggested:

- First, researchers should concentrate on reducing nonresponse by using methodological variations demonstrated to increase response rates. 
- If nonresponse remains high (above 25\%) despite these efforts, care must be taken to limit survey conclusions appropriately, given the possibility of sampling bias due to nonresponse.

- Whenever possible, researchers should attempt to assess the degree of bias introduced by nonresponse. The best way to accomplish this may be by using additional effort and resources to collect data from a random sample of the initial nonrespondents and comparing data from initial respondents to the results gathered from this group.

- Finally, in some cases (when generalizability is of particular importance and the required data are available), researchers can consider statistical procedures including sample re-weighting that may help to reduce the impact of nonresponse on results.

These strategies provide a principled plan for filling in the blind spot that arises from survey nonresponse. 
References

Achen, C. H. (1986). The statistical analysis of quasi-experiments. Berkley CA:

University of California Press.

Albaum, D.S., Evangelista, F., \& Medina, N. (1998). Role of response behavior in survey research: a cross-national study. Journal of Business Research, 42, 115-125.

Alexander, R.A., Alliger, G.M., \& Hanges, P.J. (1984). Correction for range restriction when the population variance is unknown. Applied Psychological Measurement, 8, 431437.

Alexander, R.A., Barrett, G.V., Alliger, G. M., \& Carson, K.P. (1986). Towards a general model of non-random sampling and the impact on population correlation: Generalizations of Berkson's Fallacy and restriction of range. British Journal of Mathematical and Statistical Psychology, 39, 90-105.

American Association for Public Opinion Research (2000). Standard definitions: Final dispositions of case codes and outcome rates for surveys. Retrieved May 15, 2002 from American Association for Public Opinion Research web site: http://www.aapor.org/ethics/stddef.html\#mail. 
Ary, D., Jacobs, L., \& Razavieh, A. (1996). Introduction to research in education (5 ${ }^{\text {th }}$ ed.). Fort Worth: Holt, Rinehart, and Winston.

Baldauf, A., Reisinger, H., \& Moncrief, W.C. (1999). Examining motivations to refuse in industrial mail surveys. Journal of the Market Research Society, 41, 345-353.

Berelson, B. (1949). The library's public: A report of the public library inquiry. New York: Columbia University Press.

Blake, V.L.P. (1994). Since Shaughnessy: Research methods in library and information science dissertations, 1975-1979. Collection Management, 19, 1-42.

Brehm, J. (1993). The Phantom Respondent: Opinion Surveys and Political Representation. Ann Arbor, Michigan: The University of Michigan Press.

Busha, C.H., \& Harter, S.P. (1980). Research methods in librarianship: Techniques and interpretation. New York: Academic Press.

Callison, D. (1997). Evolution of methods to measure student information use. Library \& Information Science Research, 19, 347-357.

Chen, H.C.K. (1996). Direction, magnitude, and implications of nonresponse bias in mail surveys. Journal of the Market Research Society, 38, 267-277. 
Church, A.H. (1993). Estimating the effect of incentives on mail survey response rates: A meta-analysis. Public Opinion Quarterly, 57, 62-79.

Cialdini, R.B., Vincent, J.E., Lewis, S.K., Catalan, J., Wheeler, D., \& Darby, B.L. (1975). Reciprocol concessions procedure for inducing compliance: The door-in-the-face technique. Journal of Personality and Social Psychology, 31, 206-215.

Clougherty, L., Forys, J., Lyles, T., Persson, D., Walters, C., \& Washington-Hoagland, C. (1998). The University of Iowa Libraries' undergraduate user needs assessment. College \& Research Libraries, 59(6), 572-584.

Cochran, W.G. (1963). Sampling Techniques, $2^{\text {nd }}$ Edition, New York: Wiley.

Cook, C., Health, F., and Thompson, R.L. (2000). A meta-analysis of response rates in web- or internet-based surveys. Educational and Psychological Measurement, 60, 821836.

Cook, C. \& Thompson, B. (2001). Psychometric properties of scores from the web-based LibQUAL+ study of perceptions of library service quality. Library Trends, 49, 585-604. 
Cotton, C.C., \& Wonder, B.D. (1982). Mail survey response rate and corporate size. Psychological Reports, 51(3, Pt 2), 1218.

Couper, M.P. (2000). Web surveys: A review of issues and approaches. Public Opinion Quarterly, 64, 464-494.

Crawford, G.A. \& Rice, R.E. (1997). Technology, power, and structure: Developing a model of the effects of automation on liberal arts college libraries. Library \& Information Science Research, 19, 265-300.

Cummings, S.M., Savitz, L.A. \& Konrad, T.R. (2001). Reported response rates to mailed physician questionnaires. Health Services Research, 35, 1347-1355.

Dalecki, M.G., Whitehead, J.C. \& Blomquist, G.C. (1993). Sample of nonresponse bias nd aggregate benefits in contingent valuation: An examination of early, late, and nonrespondents. Journal of Environmental Management, 38, 133-153.

Deming, W.E. (1960). Sample Design in Business Research. New York: Wiley.

Diamantopoulos, A. \& Schlegelmilch, B.B. (1996). Determinants of industrial mail survey response: A survey-on-surveys analysis of researchers' and managers' views. Journal of Marketing Management, 12, 505-531. 
Dillman, D.A. (2000). Mail and Internet Surveys: The Tailored Design Method. New York: Wiley.

Dimitroff, A. (1995). Research for special libraries: A quantitative analysis of the literature. Special Libraries, 86, 256-264.

Donald, M.N. (1960) Implications of nonresponse for the interpretation of mail questionnaire data. Public Opinion Quarterly, 24, 99-114.

Feehan, P.E., Gragg, L.W., \& Havener, M.W. (1987). Library \& Information Science Research: An analysis of the 1984 journal literature. Library \& Information Science Research, 9, 173-185.

Fidel, R. (1993). Qualitative methods in information retrieval research. Library \& Information Science Research, 15, 219-247.

Fox, R.J., Crask, M.R. \& Kim, J. (1988). Mail survey response rate: A meta-analysis of selected techniques for inducing response. Public Opinion Quarterly, 52, 467-491.

Fuller, C.H. (1974). Weighting to adjust for survey nonresponse. Public Opinion Quarterly, 38, 239-246. 
Gajraj, A.M., Faria, A.J., \& Dickinson, J.R. (1990). A comparison of the effect of promised and provided lotteries, monetary and gift incentives on mail survey response rate, speed, and cost. Journal of the Market Research Society, 32, 141-162.

Gall, M.D., Borg, W.R., \& Gall, J.P. (1996). Educational Research: An Introduction (6 $6^{\text {th }}$ ed.). White Plains, NY: Longman.

Glynn, R.J., Laird, N.M. \& Rubin, D.B. (1986). Selection modeling versus mixture modeling with nonignorable nonresponse. In H. Wainer (Ed.), Drawing ingerences from self-selected samples (pp. 115-142). New York: Springer.

Goodall, D. (1996). "It ain't what you do, it's the way that you do it:" A review of public library research with special reference to methodology. Public Library Journal, 11, 6976.

Goodman, J.S., and Blum, T.C. (1996). Assessing the non-random sampling effects of subject attrition in longitudinal research. Journal of Management, 22, 627-652.

Green, K.E. (1991). Reluctant respondents: Differences between early, late, and nonresponders to a mail survey. Journal of Experimental Education, 59, 268-276.

Green, K.E. (1996). Sociodemographic factors and mail survey response. Psychology and Marketing, 13, 171-184. 
Green, K.E., Boser, J.A., \& Hutchinson, S. R. (1998). Response-rate differences and response-enhancement effects by population type. Psychological Reports, 83, 336-338.

Groves, R.M. (1989). Survey errors and survey costs. New York: John Wiley and Sons.

Groves, R.M., Dillman, D.A., Eltinge, J.L., \& Little, R.J.A. (2001). Survey Nonresponse. New York: John Wiley and Sons.

Hart, R.L. (1998). The relationships between work roles and information gathering of the Faculty at SUNY, College at Fredonia. Library \& Information Science Research, 20, 163-185.

Heckman, J. F. (1979). Sample selection bias as a specification error. Econometrica, 47, $153-161$.

Heckman, J.F. (1976). The common structure of statistical models of truncation, sample selection, and limited dependent variables and a simple estimator for such models. Annals of Economic and Soicial Measurement, 5, 475-492.

Heckman, J.J., \& Robb, R. (1986). Alternative methods for solving the problem of selection bias in evaluating the impact of treatments on outcomes. In H. Wainer (Ed.), Drawing inferences from self-selected samples (pp. 63-107). New York: Springer. 
Helgeson, J.G., Voss, K.E., \& Terpening, W.D. (2002). Determinant of mail-survey response: Survey design factors and respondent factors. Psychology and Marketing, 19(3), 303-328.

Hernon, P., \& Schwartz, C. (2000). Survey research: A time for introspection. Library \& Information Science Research, 22, 117-122.

Holt, G. E., Elliott, D., \& Moore, A. (1999). Placing a value on public library services. Public Libraries, 38, 98-108.

Hopkins, K.D., \& Gullickson, A.R. (1992). Response rates in survey research: A metaanalysis of the effects of monetary gratuities. Journal of Experimental Education, 61, 5262.

Howell, D.C. (1997). Statistical methods for Psychology, $5^{\text {th }}$ Edition. Belmont CA: Duxbury Press.

Hox, J. J., \& De Leeuw, E.D. (1994). A comparison of nonresponse in mail, telephone and face-to-face surveys: Applying multilevel modeling to meta-analysis. Quality and Quantity, 28(4), 329-344. 
Jones, J. (1996). The effects of nonresponse on statistical inference. Journal of Health and Social Policy, 8(1), 49-62.

Julien, H. (1996). A content analysis of recent information needs and uses literature. Library \& Information Science Research, 18, 53-65.

Julien, H. \& Duggan, L. J. (2000). A longitudinal analysis of the information needs and uses literature. Library \& Information Science Research, 22(3), 291-309.

Kaldenberg, D.O., Koenig, H.F., \& Becker, B.W. (1994). Mail survey response rate patterns in a population of the elderly: Does response deteriorate with age? Public Opinion Quarterly, 58, 68-76.

Kalton, G. (1983). Introduction to survey sampling. Beverly Hills, CA: Sage.

Keeter, S., Miller,C., Kohut, A., Groves, R.M., \& Presser, S. (2000). Consequences of reducing nonresponse in a national telephone survey. Public Opinion Quarterly, 64, 125148.

Kerlinger, F.N. (1986). Foundations of Behavioral Research. New York: Holt, Rinehart and Winston. 
Kettleson, M.J. (1995). An assessment of the response rate via the Postal Service and email. Health Values: The Journal of Health Behavior, Education and Promotion, 19(2), 27-39.

Krosnick, J.A. (1999). Survey research. Annual Review of Psychology, 50, 537-567.

Krysan, M., Schuman, H., Scott, L., \& Beatty, P. (1994). Response rates and response content in mail versus face-to-face surveys. Public Opinion Quarterly, 58, 381-399.

Lakner, E. (1998). Optimizing samples for surveys of public libraries: Alternatives and compromises. Library \& Information Science Research, 20(4), 321-342.

Lindner, J.R., Murphy, T.H., \& Briers, G.E. (2001). The handling of nonresponse in agricultural education. Article presented at the $28^{\text {th }}$ Annual National Agricultural Education Research Conference, New Orleans (retrieved July 8, 2002 from the American Association for Agricultural Education web site: http://aaaeonline.ifas.ufl.edu/NAERC/2001/Papers/lindner1.pdf).

Little, R.J.A., \& Rubin, (1987). Statistical Analysis with Missing Data. New York: Wiley.

Losee, R.M., \& Worley, K.A. (1993). Research and evaluation for information professionals. San Diego, CA: Academic Press. 
Mandell, L. (1974). When to weight: Determining nonresponse bias in survey data. Public Opinion Quarterly, 38(2), 247-252.

Martin, Ch. L. (1994). The impact of topic interest on mail survey response behaviour. Journal of the Market Research Society, 36, 327-338.

McKechnie, E.F., Baker, L., Joyce, M., \& Julien, H. (2002 Forthcoming).

Methodological trends in human information research. The New Review of Information Behaviour Research: Studies of Information Seeking in Context, 3.

Neuman, W.L. (2000). Social research methods (4 ${ }^{\text {th }}$ Edition). Needham Heights, MA: Allyn and Bacon.

Palys, T. (1997). Research decisions: Quantitative and qualitative perspectives $\left(2^{\text {nd }} E d\right.$.). Toronto, Ontario: Harcourt Brace Canada.

Pearl, D.K., \& Fairley, D. (1985). Testing for the potential for nonresponse bias in sample surveys. Public Opinion Quarterly, 49, 553-560.

Perkins, G.H., \& Yuan, H. (2001). A comparison of web-based and paper-and-pencil library satisfaction survey results. College \& Research Libraries, 62, 369-377. 
Powell, R.R. (1999). Basic research methods for librarians ( $3^{\text {rd }}$ edition). Greenwich, CN: Ablex

Preitz, B.C. (1980-81). The methods of library science research: Some results from a bibliographic survey. Library Research, 2, 251-268.

Robinson, R.A., \& Agisim.P. (1951). Making mail surveys more reliable. Journal of Marketing, 15, 415-424.

Rogelberg, S.G., Luong, A., Sederbury, M.E., \& Cristol, D.S. (2000). Employee attitudes surveys: Examining the attitudes of noncompliant employees. Journal of Applied Psychology, 85(2), 284-293.

Roselle, A., \& Neufeld, S. (1998). The utility of electronic mail follow-ups for library research. Library \& Information Science Research, 20, 153-161.

Senf, J.H. (1987). The option to refuse: A tool in understanding nonresponse in mailed surveys. Evaluation Review, 11, 775-781.

Sibbald, B., Addington-Hall, J.M. , Brenneman, D., \& Freeling, P. (1994). Telephone versus postal surveys of general practitioners: Methodological considerations. British Journal of General Practitioners, 44, 297-300. 
Simpson, C.W. (1992). Technical services research, 1988-1991. Library Resources \& Technical Services, 36, 383-408.

Singer, E., Van Hoewyk, J. \& Maher, M.P. (2000). Experiments with incentives in telephone surveys. Public Opinion Quarterly, 64, 171-178.

Sosdian, C.P., \& Sharp, L.M. (1980). Nonresponse in mail surveys: Access failure or respondent resistance. Public Opinion Quarterly, 44, 396-402.

Thompson, B. (2000). Representativeness versus response rate: It ain't the response rate! Unpublished paper presented at the Association of Research Libraries (ARL) Measuring Service Quality Symposium on the New Culture of Assessment: Measuring Service Quality, October, Washington, DC.

Tomaskovic-Devey, D., Leiter, J., \& Thompson, S. (1994). Organizational survey nonresponse. Administrative Science Quarterly, 39, 439-457.

Tuckman, B.W. (1999). Conducting educational research (5 ${ }^{\text {th }}$ ed.). Fort Worth, TX: Harcourt Brace.

van Goor, H., \& Verhage, A.L. (1999). Nonresponse and recall error in a study of absence because of illness: An analysis of their effects on distributions and relationships. Quality and Quantity, 33(4), 411-428. 
van Goor, H., \& Stuiver, B. (1998). A wave-analysis of distributional bias, substantive bias and data quality in a mail survey among Dutch municipalities. Acta Politica, 33, 179-196.

Vaughan, L. (2001). Statistical Methods for the Information Professional: A Practical, Painless Approach to Understanding, Using, and Interpreting Statistics. Medford, New Jersey: Information Today.

Viswesvaran, C., Barrick, M.R., \& Ones, D.S. (1993). How definitive are conclusions based on survey data: Estimating robustness to nonresponse. Personnel Psychology, 46, $551-567$.

Visser, P.S., Krosnick, J.A., Marquette, J., \& Curtin, M. (1996). Mail surveys for election forecasting? An evaluation of the Columbus Dispatch poll. Public Opinion Quarterly, 60, $181-227$.

Wainer, H. (1989). Eelworms, bullet holes, and Geraldine Ferraro: Some problems with statistical adjustment and some solutions. Journal of Educational Statistics, 14, 121-140.

Wayne, I. (1975-76). Nonresponse, sample size, and the allocation of resources. Public Opinion Quarterly, 39(4), 557-562. 
Yammarino, F.J., Skinner, S.J., \& Childers, T.L. (1991). Understanding mail survey response behavior: A meta-analysis. Public Opinion Quarterly, 55(4), 613-639. 
Table 1 Statistics to test whether the sample is drawn from the population

\begin{tabular}{|c|c|c|c|c|}
\hline Level of & Information & Additional & Appropriate & Reference \\
\hline Measurement, & known about & Considerations & Statistic & \\
\hline Variable to be & & & & \\
\hline compared & population & & & \\
\hline Interval or & Mean and & & Z-Score & Howell \\
\hline \multirow[t]{2}{*}{ Ratio } & Standard & & & $(1997), \mathrm{p}$ \\
\hline & Deviation & & & $181-183$ \\
\hline Interval or & Mean & & One-Sample T- & Howell \\
\hline \multirow[t]{2}{*}{ Ratio } & & & test & (1997), p. \\
\hline & & & & $183-191$ \\
\hline Ordinal or & Proportion & Note distinction & Chi-Square & Howell \\
\hline \multirow[t]{5}{*}{ Nominal } & falling into & between the treatment & Goodness-of-Fit & (1997), p. \\
\hline & the different & of variables with only & test, One-Way & $146-149$ \\
\hline & groups & two categories and & Classification & \\
\hline & & those with more than & & \\
\hline & & two categories & & \\
\hline
\end{tabular}


Table 2 Statistics to test for difference between respondents and nonrespondents

\begin{tabular}{|c|c|c|c|}
\hline $\begin{array}{l}\text { Number of Levels, } \\
\text { Independent or } \\
\text { Comparison Variable }\end{array}$ & $\begin{array}{l}\text { Level of Measurement, } \\
\text { Variable of Interest }\end{array}$ & $\begin{array}{l}\text { Appropriate } \\
\text { Statistic }\end{array}$ & Reference \\
\hline 2 or more & Ordinal or Nominal & Chi-Square & $\begin{array}{l}\text { Vaughan } \\
(2001), \text { p. } 75- \\
88 \\
\text { Howell } \\
(1997), 149- \\
159\end{array}$ \\
\hline 2 & Interval or Ratio & $\begin{array}{l}\text { Independent } \\
\text { Samples t-test }\end{array}$ & $\begin{array}{l}\text { Vaughan } \\
(2001), \mathrm{p} . \\
111-122 \\
\text { Howell } \\
(1997), \mathrm{p} . \\
198-206\end{array}$ \\
\hline More than 2 & Interval or Ratio & $\begin{array}{l}\text { Between groups } \\
\text { analysis of } \\
\text { variance }\end{array}$ & $\begin{array}{l}\text { Vaughan } \\
(2001), p . \\
125-138 \\
\text { Howell } \\
(1997), p . \\
319-367\end{array}$ \\
\hline
\end{tabular}


Table 3 Recorded survey information

\begin{tabular}{|c|c|c|}
\hline Variable & $\begin{array}{l}\text { Level of } \\
\text { Measurement }\end{array}$ & Categories \\
\hline Response Rate & Ratio & \\
\hline Group Surveyed & Nominal & $\begin{array}{l}\text { Library representatives } \\
\text { Librarians } \\
\text { Users }\end{array}$ \\
\hline Type of Conclusion & Nominal & $\begin{array}{l}\text { Univariate description } \\
\text { Multivariate description } \\
\text { Model development/testing }\end{array}$ \\
\hline Method of Administration & Nominal & $\begin{array}{l}\text { Face-to-face } \\
\text { Telephone } \\
\text { Mail } \\
\text { E-mail } \\
\text { Other }\end{array}$ \\
\hline Personalization of survey materials & Nominal & $\begin{array}{l}\text { Yes } \\
\text { No }\end{array}$ \\
\hline Reminders & Nominal & $\begin{array}{l}\text { Yes } \\
\text { No }\end{array}$ \\
\hline Incentives & Nominal & $\begin{array}{l}\text { Yes } \\
\text { No }\end{array}$ \\
\hline Self addressed, stamped envelope & Nominal & $\begin{array}{l}\text { Yes } \\
\text { No }\end{array}$ \\
\hline $\begin{array}{l}\text { Nonresponse bias } \\
\text { assessment/correction }\end{array}$ & Nominal & $\begin{array}{l}\text { None } \\
\text { Comparison only } \\
\text { Comparison and correction }\end{array}$ \\
\hline
\end{tabular}


Table 4: Results by journal

\begin{tabular}{|l|l|l|l|}
\hline & C\&RL & LISR & PL \\
\hline Number of Surveys & 45 & 17 & 14 \\
(percent of total) & $(59.2 \%)$ & $(22.4 \%)$ & $(18.4 \%)$ \\
\hline $\begin{array}{l}\text { Average Response Rate } \\
\text { (s.d.) }\end{array}$ & $62.4 \%$ & $67.5 \%$ & $58.8 \%$ \\
\hline $\begin{array}{l}\text { Number of surveys with } \\
\text { Response Rate above 75\% } \\
\text { (percent within group) }\end{array}$ & $(18.5 \%)$ & $(16.7 \%)$ & $(22.2 \%)$ \\
\hline
\end{tabular}


Table 5: Results by year

\begin{tabular}{|c|c|c|c|c|c|c|}
\hline & 1996 & 1997 & 1998 & 1999 & 2000 & 2001 \\
\hline $\begin{array}{l}\text { Number of } \\
\text { Surveys (percent } \\
\text { of total) }\end{array}$ & $19(25 \%)$ & $\begin{array}{l}11 \\
(14.5 \%)\end{array}$ & $\begin{array}{l}13 \\
(17.1 \%)\end{array}$ & $\begin{array}{l}17 \\
(22.4 \%)\end{array}$ & $\begin{array}{l}11 \\
(14.5 \%)\end{array}$ & $5(6.6 \%)$ \\
\hline $\begin{array}{l}\text { Average } \\
\text { Response Rate } \\
\text { (s.d.) }\end{array}$ & $\begin{array}{l}69 \% \\
(10.1 \%)\end{array}$ & $\begin{array}{l}62 \% \\
(20.2 \%)\end{array}$ & $\begin{array}{l}66 \% \\
(15.4 \%)\end{array}$ & $\begin{array}{l}53 \% \\
(26.4 \%)\end{array}$ & $\begin{array}{l}63 \% \\
(13.9 \%)\end{array}$ & $\begin{array}{l}68 \% \\
(31.8 \%)\end{array}$ \\
\hline $\begin{array}{l}\text { Number of } \\
\text { surveys with } \\
\text { Response Rate } \\
\text { above } 75 \% \\
\text { (percent within } \\
\text { group) }\end{array}$ & $\begin{array}{l}5 \\
(26.3)\end{array}$ & $\begin{array}{l}3 \\
(27.3)\end{array}$ & $\begin{array}{l}4 \\
(30.8)\end{array}$ & $\begin{array}{l}4 \\
(23.5)\end{array}$ & $\begin{array}{l}2 \\
(18.2)\end{array}$ & $\begin{array}{l}3 \\
(60.0)\end{array}$ \\
\hline
\end{tabular}


Table 6: Results by population type

\begin{tabular}{|l|l|l|l|}
\hline & $\begin{array}{l}\text { Library } \\
\text { representatives }\end{array}$ & Librarians & Users \\
\hline $\begin{array}{l}\text { Number of Surveys } \\
\text { (percent of total) }\end{array}$ & 32 & 21 & 23 \\
\hline Average Response Rate & $(42.1 \%)$ & $(27.6 \%)$ & $(20.3 \%)$ \\
\hline $\begin{array}{l}\text { Number of surveys with Response } \\
\text { Rate above 75\% } \\
\text { (percent within group) }\end{array}$ & $72.0 \%(11.5 \%)$ & $65.0 \%$ & $49.0 \%$ \\
\hline
\end{tabular}


Table 7: Results by research goal

\begin{tabular}{|l|l|l|l|}
\hline & $\begin{array}{l}\text { Univariate } \\
\text { Description }\end{array}$ & $\begin{array}{l}\text { Multivariate } \\
\text { description }\end{array}$ & $\begin{array}{l}\text { Model testing or } \\
\text { development }\end{array}$ \\
\hline $\begin{array}{l}\text { Number of Surveys } \\
\text { (percent of total) }\end{array}$ & 30 & 37 & 9 \\
\hline Average Response Rate & $59.1 \%$ & $65.1 \%$ & $(11.8 \%)$ \\
$($ s.d.) & $(22.2 \%)$ & $(16.6 \%)$ & $(19.6 \%)$ \\
\hline $\begin{array}{l}\text { Number of surveys with } \\
\text { Response Rate above } 75 \%\end{array}$ & 8 & 9 & 4 \\
(percent within group) & $(26.7 \%)$ & $(24.3 \%)$ & $(44.4 \%)$ \\
\hline
\end{tabular}




\section{Appendix 1: List of Articles with Surveys Meeting Inclusion Criteria}

1. Immroth, B. F., \& Lance, K. C. (1996). Output measures for children's services in public libraries. Public Libraries, 35, 240-245.

2. Chelton, M. K. (1997). Three in five public library users are youth: Implications of survey results from the National Center for Education Statistics. $\underline{\text { Public }}$ Libraries , 36, 104-108.

3. Johnson, C. P. (1998). Library employees without the ALA-accredited Master's degree. Public Libraries, 37, 40-46.

4. Baker, L. M., Spang, L., \& Gogolowski, C. (1998). The provision of consumer health information by Michigan Public Librarians. Public Libraries, 37, 250255.

5. Holt, G. E., Elliott, D., \& Moore, A. (1999). Placing a value on public library services. Public Libraries, 38, 98-108.

6. Gregory, G. (1999). The Library Services and Technology Act: How changes from LSCA are affecting libraries. Public Libraries, 38, 378-382.

7. Liu, Y. Q., \& Zweizig, D. (2000). Public library use of statistics: A survey report. Public Libraries, 39, 98-105.

8. Crawford, G. A. (2000). Internet issues: Access, filtering, and a survey of Pennsylvania public libraries. Public Libraries, 39, 162-167.

9. Gilton, D. G. (2000). Onward and upward: Promotion of public librarians. Public Libraries, 39, 214-219.

10. The Public Libraries Committee of the New England Music Library Association. (2000). Music collection and acquisition practices in Connecticut public libraries. Public Libraries, 39, 348-355.

11. Staples, S. (2001). Fast and slow lanes of the information highway: Librarian decision making about electronic information services. Public Libraries, 40, 294-297.

12. Karp, R., \& Keck, A. (1996). Theological librarianship: Toward a profile of a profession. College \& Research Libraries, 57, 35-42.

13. Farr, K. W., \& Scott, R. N. (1996). Earnings determinants of library faculty in the University System of Georgia. College \& Research Libraries, 57, 77-87.

14. Allen, F. R. (1996). Materials budgets in the electronic age: A survey of academic libraries. College \& Research Libraries, 57, 133-143. 
15. Hurd, J. M. (1996). ARL academic science and technology libraries: Report of a survey. College \& Research Libraries, 57, 144-160.

16. Hseih-Yee, I. (1996). Student use of online catalogs and other information channels. College \& Research Libraries, 57, 161-175.

17. Metz, P., \& Stemmer, J. (1996). A reputational study of academic publishers. College \& Research Libraries, 57, 234-248.

18. Dilmore, D. H. (1996). Librarian/faculty interaction at nine New England colleges. College \& Research Libraries, 57, 274-284.

19. Koenig, M. E., Morrison, R., \& Roberts, L. (1996). Faculty status for library professionals: Its effect on job turnover and job satisfaction among university research library directors. College \& Research Libraries, 57, 295300.

20. Patterson, L., \& Taylor, R. H. (1996). Tribally controlled community college libraries: A paradigm for survival. College \& Research Libraries, 57, 316329.

21. Via, B. J. (1996). Publishing in the journal literature of Library and Information Science: A survey of manuscript review processes and acceptance. College \& Research Libraries, 57, 365-376.

22. Carrigan, D. P. (1996). Data-guided collection development: A promise unfulfilled. College \& Research Libraries, 57, 429-437.

23. Smith, N., \& Tibbo, H. R. (1996). Libraries and the creation of electronic texts for the humanities. College \& Research Libraries, 57, 535-553.

24. Carpenter, S. (1996). The Americans with Disabilities Act: Accommodation in Ohio. College \& Research Libraries, 57, 555-566.

25. Thornton, J. K. (1997). Carpal Tunnel Syndrom in ARL libraries. College \& Research Libraries, 58, 9-18.

26. Leckie, G. L., \& Brett, J. (1997). Job satisfaction of Canadian university librarians: A national survey. College \& Research Libraries, 58, 31-47.

27. Coleman, V., Xiao, Y. D., Bair, L., \& Chollett, B. (1997). Toward a TQM paradigm: Using SERVQUAL to measure library service quality. College \& Research Libraries, 58, 237-251.

28. Baldwin, V. A., Gibbs, W. J., \& Slough, M. M. (1997). Initiating an effective personnel development program. College \& Research Libraries, 58, 267277. 
29. Kirkland, J. J. (1997). The missing women library directors: Deprivation versus mentoring. College \& Research Libraries, 58, 376-384.

30. Libby, K. A. , \& Caudle, D. M. (1997). A survey on the outsourcing of cataloging in academic libraries. College \& Research Libraries, 58, 550-560.

31. Hassard Wilkins, J. L., \& Leckie, G. J. (1997). University professional and managerial staff: Information needs and seeking. College \& Research Libraries, 58, 561-574.

32. Kirkpatrick, T. E. (1998). The training of academic library staff on information technology within the libraries of the Minnesota State Colleges and Universities system. College \& Research Libraries, 59, 51-59.

33. O'Keefe, J. (1998). Small college library directors: Getting in the door and surviving on the job. College \& Research Libraries, 59, 140-153.

34. Andaleeb, S. S., \& Simmonds, P. L. (1998). Explaining user satisfaction with academic libraries: Strategic implications. College \& Research Libraries, 59, 156-167.

35. Buttlar, L., \& Garcha, R. (1998). Catalogers in academic libraries: Their evolving and expanding roles. College \& Research Libraries, 59, 311-321.

36. Bell, S. J., \& Cronin-Kardon, C. (1998). Making the library management systems acquisition: Achieving resolution of a tough decision. College \& Research Libraries, 59, 348-361.

37. Preston, C. (1998). Perceptions of discriminatory practices and attitudes: A survey of African American librarians. College \& Research Libraries, 59, 434-445.

38. Leyson, H. M., \& Black, W. K. (1998). Peer review in Carnegie research libraries. College \& Research Libraries, 59, 512-522.

39. Clougherty, L., Forys, J., Lyles, T., Persson, D., Walters, C., \& WashingtonHoagland, C. (1998). The University of Iowa Libraries' undergraduate user needs assessment. College \& Research Libraries, 59, 572-584.

40. Leckie, G., \& Fullerton, A. (1999). Information literacy in science and engineering undergraduate education: Faculty attitudes and pedagogical practices. College \& Research Libraries, 60, 9-29.

41. Mitchell, B. , \& Reichel, M. (1999). Publish or perish: A dilemma for academic librarians? College \& Research Libraries, 60, 232-243.

42. Neely, T. Y. , \& Winston, M. D. (1999). Snowbird Leadership Institute: leadership development in the profession. College \& Research Libraries, 60, 412-425. 
43. Brown, C. (1999). Information literacy of physical science graduate students in the information age. College \& Research Libraries, 60, 426-438.

44. Hart, R. L. (1999). Scholarly publication by university librarians: A study at Penn State. College \& Research Libraries, 60, 454-462.

45. Lawson, K. G., \& Pelzer, N. L. (1999). Assessing technology-based projects for promotion and/or tenure in ARL academic libraries. College \& Research Libraries, 60, 464-476.

46. Bordeianu, S., \& Seiser, V. (1999). Paraprofessional catalogers in ARL libraries. College \& Research Libraries, 60, 532-540.

47. Haines, A. (1999). Librarians' personal web pages: An analysis. College \& Research Libraries, 60, 543-550.

48. Weingart, S. J., \& Anderson, J. A. (2000). When questions are answers: Using a survey to achieve faculty awareness of the library's electronic resources. College \& Research Libraries, 61, 127-134.

49. Winston, M. D., \& Li, H. (2000). Managing diversity in liberal arts college libraries. College \& Research Libraries, 61, 205-215.

50. Thornton, J. K. (2000). Job satisfaction of librarians of African descent employed in ARL academic libraries. College \& Research Libraries, 61, 217-232.

51. Tenopir, C., \& Read, E. (2000). Patterns of database use in academic libraries. College \& Research Libraries, 61, 234-246.

52. Julien, H. (2000). Information literacy instruction in Canadian academic libraries: Longitudinal trends and international comparisions . College \& Research Libraries, 61, 510-523.

53. Maughan, P. D. (2001). Assessing information literacy among undergraduates: A discussion of the literature and the University of California-Berkeley assessment experience. College \& Research Libraries, 62, 71-85.

54. Herring, S. D. (2001). Faculty acceptance of the World Wide Web for student research. College \& Research Libraries, 62, 251-258.

55. Brewer, J., \& Winston, M. D. (2001). Program Evaluation for Internship/residency Programs in Academic and Research Libraries. College \& Research Libraries, 62, 307-315.

56. Baker, L. M. (1996). A study of the nature of information needed by women with multiple sclerosis. Library \& Information Science Research, 19, 67-81.

57. Cullen, R., \& Calvery, P. (1996). New Zealand university libraries effectiveness 
project: Dimensioins and concepts of organizational effectiveness. Library \& Information Science Research, 18, 99-119.

58. Affleck, M. A. (1996). Burnout among bibliographic instruction librarians. Library \& Information Science Research , 18, 165-183.

59. Alafiatayo, B. O., \& Yip, Y. P. (1996). Reference transaction and the nature of the process for general reference assistance. Library \& Information Science Research, 18, 357-384.

60. Crawford, G. A., \& Rice, R. E. (1997). Technology, power, and structure: Developing a model of the effects of automation on liberal arts college libraries. Library \& Information Science Research, 19, 265-300.

61. Kaminer, N. (1997). Scholars and the use of the Internet. Library \& Information Science Research, 19, 329-345.

62. Cha, M., \& Pungitore, V. L. (1998). Compliance with public library standards in the State of Ohio. Library \& Information Science Research, 20, 69-98.

63. Hart, R. (1998). The relationships between work foles and information gathering of the faculty at SUNY, College at Fredonia. Library \& Information Science Research, 20, 163-185.

64. Nilsen, K. (1998). Social science research in Canada and government information policy: The Statistics Canada example. Library \& Information Science Research, 20, 211-234.

65. Travica, B. (1999). Organizational aspects of the virtual library: A survey of academic libraries. Library \& Information Science Research, 21, 173-203.

66. Wicks, D. A. (1999). The information-seeking behavior of pastoral clergy: A study of the interaction of their work worlds an work roles. Library \& Information Science Research, 21, 205-226.

67. Chu, C. M. (1999). Literary critics at work and their information needs: A researchphases model. Library \& Information Science Research, 21, 247-273.

68. Bertot, J. C., \& McClure, C. R. (1999). U.S. public library outlet Internet connectivity: Progress and strategies. Library \& Information Science Research, 21, 281-298.

69. Sierpe, E. (1999). Job satisfaction among librarians in English-language universities in Quebec. Library \& Information Science Research, 21, 479-499.

70. Curry, A., \& Curtis, A. (2000). Connecting to the Internet: The challenge for Canada's county and regional libraries. Library \& Information Science Research, 22, 77-103. 
71. Majid, S., Anwar, M. A., \& Eisenschitz, T. S. (2000). Information needs and information seeking behavior of agricultural scientists in Malaysia. Library \& Information Science Research, 22, 145-163.

72. Meho, L. I., \& Haas, S. W. (2001). Information-seeking behavior and use of social science faculty studying stateless nations: A case study. Library \& Information Science Research, 23, 5-25. 